\title{
Attributes and perspectives of public providers related to provision of medical abortion at public health facilities in Vietnam: a cross-sectional study in three provinces
}

\author{
This article was published in the following Dove Press journal: \\ International Journal of Women's Health \\ 14 August 2014 \\ Number of times this article has been viewed
}

\author{
Thoai D Ngo ${ }^{1,2}$ \\ Caroline Free' \\ Hoan T Le ${ }^{3}$ \\ Phil Edwards' \\ Kiet HT Pham ${ }^{4}$ \\ Yen BT Nguyen ${ }^{4}$ \\ Thang H Nguyen ${ }^{5}$ \\ 'Faculty of Epidemiology and \\ Population Health, London \\ School of Hygiene and Tropical \\ Medicine, London, UK; ${ }^{2}$ Research, \\ Monitoring and Evaluation Team, \\ Health System Department, Marie \\ Stopes International, London, UK; \\ ${ }^{3}$ Department of Environmental Health, \\ ${ }^{4}$ Department of Health Economics, \\ Hanoi Medical University, ${ }^{5}$ Research \\ and Metrics Team, Marie Stopes \\ International Vietnam, Hanoi, Vietnam
}

Correspondence: Thoai D Ngo Research, Monitoring and Evaluation Team, Health System Department, Marie Stopes International, I Conway

Street, London, WIT 6LP, UK

Tel +442070342352

Fax +442070342372

Email thoai.ngo@mariestopes.org
Background: The purpose of this study was to investigate attributes of public service providers associated with the provision of medical abortion in Vietnam.

Methods: We conducted a cross-sectional study via interviewer-administered questionnaire among abortion providers from public health facilities in Hanoi, Khanh Hoa, and Ho Chi Minh City in Vietnam between August 2011 and January 2012. We recruited abortion providers at all levels of Vietnam's public health service delivery system. Participants were questioned about their medical abortion provision practices and perspectives regarding abortion methods.

Results: A total of 905 providers from 62 health facilities were included, comprising 525 (58.0\%) from Hanoi, 122 (13.5\%) from Khanh Hoa, and 258 (28.5\%) from Ho Chi Minh City. The majority of providers were female (96.7\%), aged $\geq 25$ years $(94 \%)$, married $(84.4 \%)$, and had at least one child $(89 \%) ; 68.9 \%$ of providers offered only manual vacuum aspiration and $31.1 \%$ performed both medical abortion and manual vacuum aspiration. Those performing both methods included physicians (74.5\%), midwives (21.7\%), and nurses (3.9\%). Unadjusted analyses showed that female providers (odds ratio $0.1 ; 95 \%$ confidence interval $0.01-0.30$ ) and providers in rural settings (odds ratio $0.3 ; 95 \%$ confidence interval $0.08-0.79$ ) were less likely to provide medical abortion than their counterparts. Obstetricians and gynecologists were more likely to provide medical abortion than providers with nursing/midwifery training (odds ratio $22.2 ; 95 \%$ confidence interval 3.81-129.41). The most frequently cited advantages of medical abortion for providers were that no surgical skills are required $(61.7 \%)$ and client satisfaction is better $(61.0 \%)$.

Conclusion: Provision of medical abortion in Vietnam is lower than provision of manual vacuum aspiration. While the majority of abortion providers are female midwives in Vietnam, medical abortion provision is concentrated in urban settings among physicians. Individuals providing medical abortion found that the method yields high client satisfaction.

Keywords: Vietnam, medical abortion, misoprostol, mifepristone, health service delivery, surgical abortion

\section{Introduction}

The advent of manual vacuum aspiration (MVA) in the 1960s represented a major development for primary prevention of complications of unsafe abortion in resourcelimited countries. This technology uses a simple syringe with a plunger to generate negative pressure for uterine evacuation. MVA is especially suited for use in clinics located in resource-limited settings because the equipment can be cleaned, disinfected, and sterilized for repeated use. ${ }^{1}$ MVA has become the recommended method for 
uterine evacuation in abortion procedures before 12 weeks of pregnancy. ${ }^{1}$

Since the discovery of prostaglandins in early 1969 and anti-progesterone in the $1980 \mathrm{~s}$, medical abortion (MA) has become an alternative method for first trimester abortion ( $\leq 9$ weeks' gestation). ${ }^{2,3}$ Medical methods using a mifepristone and misoprostol regimen for first trimester abortion have been shown to be both safe and effective. ${ }^{4}$ The recommended World Health Organization regimen for MA based on compiled evidence is $200 \mathrm{mg}$ of mifepristone followed by $800 \mu \mathrm{g}$ of misoprostol $36-48$ hours later. ${ }^{4,5}$

In 1992, MA was introduced in Vietnam via a clinical study to expand choice and access to abortion services. ${ }^{6}$ Clinical trials have since reported high efficacy and acceptability rates for first trimester MA. ${ }^{7-9}$ However, a 2002 survey revealed that the national percentage of abortions using MA was only 5\% compared with $86 \%$ for surgical abortion (MVA). ${ }^{10}$ It is unclear why MA is not more widely provided in Vietnam.

The public health system in Vietnam operates at four administrative levels, ie, community, district, province, and state (Figure 1). Community health stations form the primary unit of the health care system, delivering primary care at the local level; $94 \%$ of communities have their own community health stations. ${ }^{11}$ Embedded in the state health system, reproductive health services are available at all administrative levels. Parallel to the standard public health system, there are centers for reproductive health at the provincial and district health levels that focus on preventive measures such as family planning service provision and comprehensive abortion care. A surgical termination service using MVA exists at all Vietnam's public health administration levels and is provided by midwives. However, MA using a mifepristone + misoprostol regimen for first trimester termination is only permitted at the central, provincial, and district levels, and is performed by obstetricians/gynecologists. ${ }^{6}$ MA services are provided at centers for reproductive health, abortion clinics in hospitals, and specialized hospitals at these administrative levels (central, provincial, district) located in urban and periurban areas.

For MA to be widely adopted, the method must be acceptable to providers. Thus, it is important to identify factors that may affect provider acceptability of MA. Provider sex has been shown to influence attitudes towards provision of abortion services. ${ }^{12}$ A study in India showed that female abortion providers were more likely to include MA in their routine practice than male providers. ${ }^{7}$ In addition, private providers have been found to offer MA more often than public providers and to be more familiar with MA drugs than public providers. ${ }^{13}$

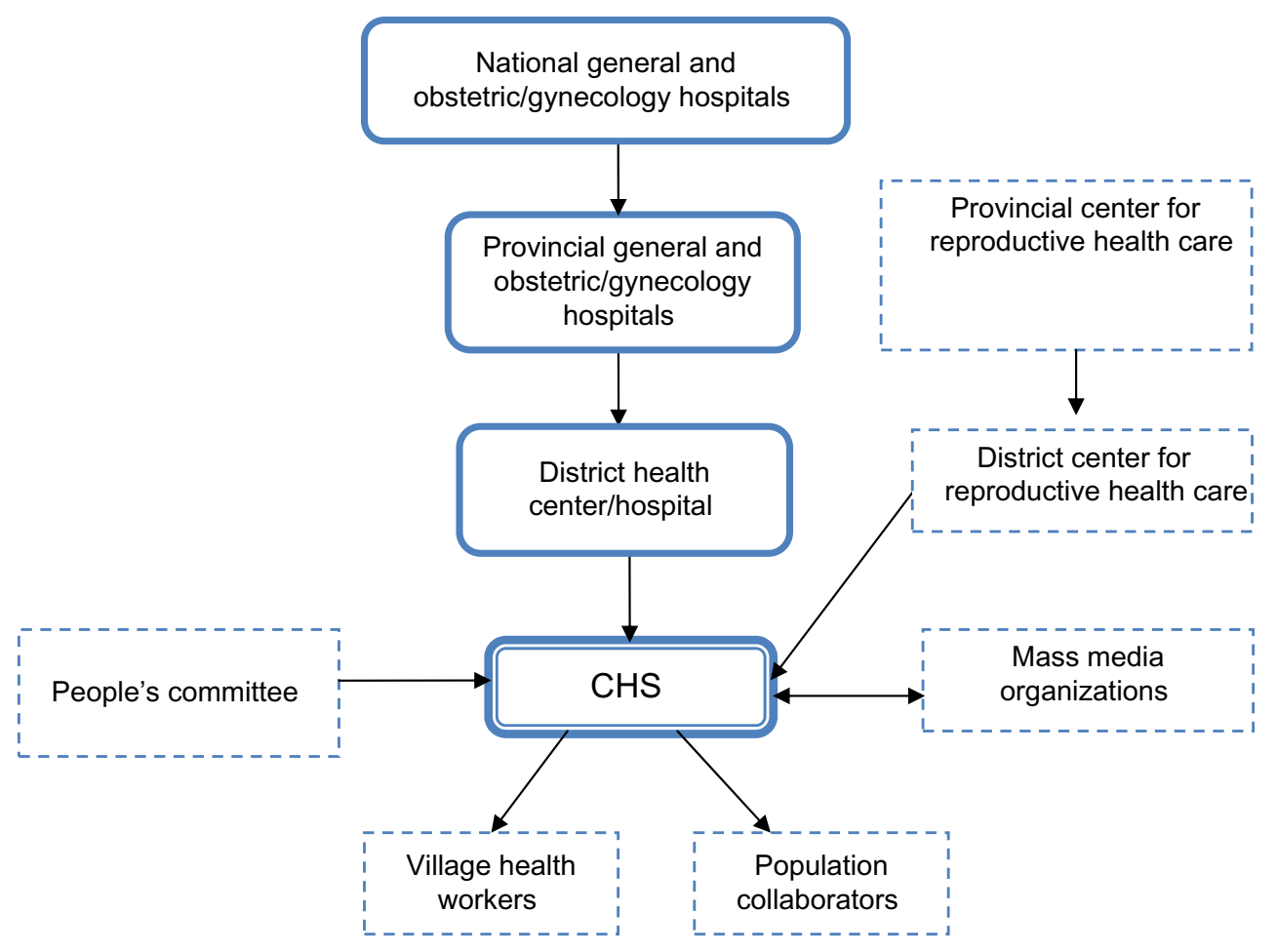

Figure I Public reproductive health service delivery system in Vietnam. Abbreviation: CHS, community health station. 
Berer reported that MA is perceived as more feasible for providers than MVA because it does not require special equipment, aseptic conditions, or extensive training. ${ }^{14}$ Other studies have suggested that a lack of knowledge and training may be a barrier to providing MA. ${ }^{15,16}$ The amount of time spent in clinical supervision appears to play a critical role in provider acceptability of MA in that providers believe home-based use of misoprostol requires less clinical supervision time than facility-based administration. ${ }^{17-20}$ Provider perceptions of the safety and efficacy of abortion methods may also affect the choice of methods provided. ${ }^{14}$ Where the health service provider is covering the cost, clinicians and managers may prefer the cheaper option. ${ }^{14}$

Limited information is available on current perspectives and provision practices regarding MA among abortion providers in Vietnam. Updated information may help identify factors that affect the acceptability and feasibility of current MA service delivery at a national level. The objective of this study was to identify factors possible affecting which public abortion providers in Vietnam offer MA by examining current MA practices and perspectives of abortion providers working in the public health system in Hanoi, Khanh Hoa, and Ho Chi Minh City.

\section{Materials and methods}

A cross-sectional quantitative survey was conducted among abortion providers at public health facilities in Hanoi municipality, Khanh Hoa province, and Ho Chi Minh City from August 2011 to January 2012. A multistage sampling strategy was used to select provinces, health facilities, and providers. Selected provinces/municipalities represented geographic and cultural differences within the country.

Facilities included were: central specialist sexual reproductive health/general hospitals; provincial specialist/general hospitals; provincial centers for reproductive health; district hospitals; district centers for reproductive health; and community health stations. A master list of all health facilities in the three regions was obtained from the municipal and provincial departments of health. All specialist hospitals and centers specializing in service provision for sexual reproductive health were selected, due to limited numbers of these facilities at each health administrative level. A random sampling strategy was used to select $50 \%$ of all facilities that were not specialized in reproductive health (general hospitals, community health stations). In total, 62 health facilities were included. This sampling method has been described previously. ${ }^{21}$

Eligible providers including physicians and midwives providing MVA, MA, or both at any of the selected facilities were invited to participate. Participation was voluntary, and providers taking part in the study provided their written informed consent prior to participation. The survey was conducted using a structured questionnaire administered face-toface by an interviewer in a private office at the participant's place of work. Providers at community health stations were invited to the district general hospital associated with their community health station to participate. The questionnaire canvassed the information provider's sociodemographic characteristics, knowledge and attitudes towards abortion, termination service provision and skills, and perceptions of termination services.

The sample size was calculated with the assumption that at least $50 \%$ of providers administer MA and MVA. With 783 providers, the sample size was calculated to detect the proportion of abortion providers performing MA within $\pm 5 \%$ of its true value with a $95 \%$ confidence interval (CI). Allowing for a $10 \%$ nonresponse rate, the sample size increased to 862 . The study was granted ethical approval by the institutional review boards at the London School of Hygiene and Tropical Medicine and the Hanoi School of Public Health (number 5952; approved May 5, 2011).

Because the proportion of health facilities sampled (primary sampling unit) was not constant $(100 \%$ of sexual reproductive health specialist facilities versus $50 \%$ of general facilities), respondents did not have an equal chance of selection. Providers at general hospitals were half as likely to be included as providers at specialist sexual reproductive health facilities. Therefore, in the analysis, providers at general facilities were given twice the weight of providers from specialist sexual reproductive health facilities.

\section{Statistical analysis}

All analyses were performed using Stata survey commands to adjust for this sampling scheme and probability weights. Descriptive statistics were used to summarize characteristics and provision practices. The chi-square test was used for binomial variables and the Student's $t$-test was used for continuous variables. Factors that might be associated with the provision of MA (provider's sex, location, medical training, and facility where they spend the most time) were assessed using logistic regression. Statistical analyses were performed using Stata version 11.1 (StataCorp LP, College Station, TX, USA). In this paper, we report our findings regarding MA provision practices and provider perspectives regarding abortion methods. Findings regarding providers' knowledge of MA are described in a separate paper. ${ }^{15}$ 


\section{Results}

\section{Provider characteristics}

A total of 905 providers were included in the survey, ie, 525 (58.0\%) from Hanoi, 122 (13.5\%) from Khanh Hoa, and $258(28.5 \%)$ from Ho Chi Minh City; $58.3 \%$ came from community health stations, $16.6 \%$ were from district centers for reproductive health, $13.4 \%$ were from district hospitals, and the remainder were from provincial specialist/ general hospitals, centers for reproductive health, or central specialist/general hospitals. The survey response rate was $99.6 \%$.

Most providers were midwives (74.9\%) and 23\% were doctors. Of the three regions, Hanoi had the highest proportion of doctors. The majority of providers were female (96.7\%), aged $\geq 25$ years (94\%), married ( $84.4 \%$ ), and had at least one child (89\%). There was an even distribution of providers between urban/periurban and rural areas $(51.0 \%$ versus $49.0 \%$, respectively). Of the 905 providers, $31.1 \%$ performed both MA and MVA, while $68.9 \%$ performed MVA only. The proportion performing both methods varied by region, being $12.1 \%$ in Khanh Hoa, 27.1\% in Ho Chi Minh City, and $36.8 \%$ in Hanoi.

\section{Relationship between provider characteristics and provision of MA}

The group performing MA and MVA contained a significantly greater proportion of physicians than the group that performed MVA only ( $74.5 \%$ versus $0 \% ; P=0.002$, Table 1$)$.

In contrast, midwives comprised $21.7 \%$ of the group that performed MA and MVA, and $99.5 \%$ of the group that performed MVA only $(P=0.002)$. The majority $(90.4 \%)$ of providers in the group performing MA and MVA were female. Compared with providers who performed MVA only, a significantly higher proportion of providers performing both methods were male $(9.6 \%$ versus $0.5 \% ; P=0.001)$, and married $(90.3 \%$ versus $82.7 \% ; P=0.043)$. The proportion of providers in urban/periurban settings was higher in the group that performed MA and MVA than in the group that performed MVA only ( $73.3 \%$ versus $40.9 \%$; $P=0.021$ ).

There was a higher proportion of providers with midwifery training in the group that offered MVA only than in the group performing both methods $(88.5 \%$ versus $26.0 \%$; $P<0.001)$. The inverse was observed for those with general or specialist (obstetrics and gynecology) medical training. Providers who performed both methods spent more time working in a private health facility than those who only provided MVA (Table 1).
Table I Providers' sociodemographic and provision characteristics, by termination service provision $(n=905)$

\begin{tabular}{|c|c|c|c|}
\hline \multirow[t]{3}{*}{ Characteristics } & \multicolumn{2}{|c|}{$\begin{array}{l}\text { Termination service } \\
\text { provision }\end{array}$} & \multirow[t]{3}{*}{$P$-value* } \\
\hline & $\begin{array}{l}\text { Medical and } \\
\text { surgical } \\
(n=255)\end{array}$ & $\begin{array}{l}\text { Surgical } \\
\text { only } \\
(n=646)\end{array}$ & \\
\hline & $\%$ & $\%$ & \\
\hline \multicolumn{4}{|l|}{ Sociodemographic } \\
\hline \multicolumn{4}{|l|}{ Region } \\
\hline Hanoi & 69.4 & 53.6 & \\
\hline Khanh Hoa & 5.1 & 15.4 & \\
\hline Ho Chi Minh City & 25.5 & 31.0 & 0.233 \\
\hline \multicolumn{4}{|l|}{ Types of provider } \\
\hline $\begin{array}{l}\text { Doctors (obstetrics/ } \\
\text { gynecology) }\end{array}$ & 74.5 & 0 & \\
\hline Midwives & 21.7 & 99.5 & \\
\hline Nurses & 3.9 & 0.5 & 0.002 \\
\hline \multicolumn{4}{|l|}{ Sex } \\
\hline Male & 9.6 & 0.5 & \\
\hline Female & 90.4 & 99.5 & 0.001 \\
\hline \multicolumn{4}{|l|}{ Age (years) } \\
\hline$\leq 24$ & 2.9 & 6.8 & \\
\hline $25-34$ & 24.9 & 37.4 & \\
\hline $35-44$ & 31.4 & 22.4 & \\
\hline $45+$ & 40.8 & 33.4 & 0.102 \\
\hline \multicolumn{4}{|l|}{ Marital status } \\
\hline Single (never married) & 8.2 & 15.4 & \\
\hline Married/living with partner & 90.3 & 82.7 & \\
\hline Divorced/separated & 1.5 & 1.9 & 0.043 \\
\hline \multicolumn{4}{|l|}{ Number of children } \\
\hline 0 & 7.6 & 12.6 & \\
\hline I & 29.9 & 28.6 & \\
\hline 2 & 59.2 & 53.6 & \\
\hline $3-4$ & 3.2 & 5.3 & 0.164 \\
\hline \multicolumn{4}{|l|}{ Location } \\
\hline Urban/periurban & 73.3 & 40.9 & \\
\hline Rural & 26.7 & 59.1 & 0.021 \\
\hline \multicolumn{4}{|c|}{ Provision history and characteristics } \\
\hline \multicolumn{4}{|l|}{ Medical training received } \\
\hline Nursing & 3.9 & 3.1 & \\
\hline Midwifery & 26.0 & 88.5 & \\
\hline $\begin{array}{l}\text { Obstetrics/gynecology } \\
\text { specialist }\end{array}$ & 34.1 & 1.2 & \\
\hline $\begin{array}{l}\text { Other medical } \\
\text { doctoral degree }\end{array}$ & 36.0 & 7.1 & $<0.00$ I \\
\hline \multicolumn{4}{|l|}{ Years of experience } \\
\hline$\leq \mathrm{I}$ year & 6.4 & 8.6 & \\
\hline $2-9$ years & 35.5 & 39.6 & \\
\hline $10-19$ years & 25.2 & 23.5 & \\
\hline $20-29$ years & 27.3 & 20.8 & \\
\hline $30-37$ years & 5.8 & 7.5 & 0.520 \\
\hline \multicolumn{4}{|c|}{ Facility where providers spend the most time } \\
\hline At private/other facility & 1.2 & 1.8 & \\
\hline At the current facility & 88.3 & 96.9 & \\
\hline $\begin{array}{l}\text { At private and public } \\
\text { facility equally }\end{array}$ & 10.4 & 1.3 & 0.004 \\
\hline
\end{tabular}

Note: $* P$-values for differences between the two groups. 
Table 2 Odds ratios and 95\% confidence intervals from unadjusted logistic regression to identify variables associated with MA provision

\begin{tabular}{|c|c|c|}
\hline Provider characteristics & $\begin{array}{l}\text { Unadjusted OR } \\
\text { for MA provision } \\
\text { OR }(95 \% \mathrm{Cl})\end{array}$ & $\begin{array}{l}P \text {-value for } \\
\text { unadjusted } \\
\text { OR }\end{array}$ \\
\hline \multicolumn{3}{|l|}{ Sex } \\
\hline Male & 1.0 & \\
\hline Female & $0.1(0.0 I-0.30)$ & $\leq 0.001$ \\
\hline \multicolumn{3}{|l|}{ Location } \\
\hline Urban/periurban & 1.0 & \\
\hline Rural & $0.3(0.08-0.79)$ & 0.048 \\
\hline \multicolumn{3}{|l|}{ Medical training received } \\
\hline Nursing & 1.0 & \\
\hline Midwifery & $0.2(0.03-2.18)$ & 0.058 \\
\hline Obstetrics/gynecology specialist & $22.2(3.8 I-\mid 29.4 I)$ & 0.002 \\
\hline Other medical doctoral degree & $4.0(1.02-16.04)$ & 0.021 \\
\hline \multicolumn{3}{|c|}{ Facility where providers spend the most time } \\
\hline At private/other facility & 1.0 & \\
\hline At the current facility & $1.4(0.73-10.04)$ & 0.729 \\
\hline $\begin{array}{l}\text { At private and public } \\
\text { facility equally }\end{array}$ & $12.3(0.67-226.04)$ & 0.081 \\
\hline
\end{tabular}

Abbreviations: $\mathrm{MA}$, medical abortion; $\mathrm{OR}$, odds ratio; $\mathrm{Cl}$, confidence interval.

Unadjusted logistic regression analyses were performed to assess the effect of the provider's sex, location, medical training received, and facility where they worked the most ( coded MA + MVA $=1$ versus MVA $=0$ ) on provision of MA. Unadjusted analyses showed that female providers (odds ratio [OR] $0.1 ; 95 \%$ CI $0.01-0.30$ ) and individuals located in rural settings (OR $0.3 ; 95 \%$ CI $0.08-0.79$ ) were less likely to provide MA than their counterparts. Specialists in obstetrics and gynecology had higher odds of MA provision than providers with nursing/midwifery training (OR 22.2; 95\% CI 3.81-129.41). The type of facility (public or private) in which the providers worked the most did not have an effect on MA provision (Table 2).

\section{MA provision practices among providers performing both MA and MVA}

Subgroup analysis was conducted among providers who performed both MA and MVA ( $\mathrm{n}=255)$. During the previous week, $15.9 \%$ had performed at least one MA procedure, $12.6 \%$ had performed at least ten procedures, and most $(71.5 \%)$ had not performed any MA procedures. The distribution was similar for MVA (Table 3). For MA, the majority of providers $(86.2 \%)$ instructed women to administer misoprostol at home, while $13.8 \%$ asked women to return to the health facility for administration of misoprostol. There was no statistically significant difference between the amount of money the providers charged for MA (mean USD23;
Table 3 Medical abortion provision practices among providers who offer both medical abortion and surgical abortion

\begin{tabular}{|c|c|}
\hline \multirow[t]{2}{*}{ Provision practices } & $\begin{array}{l}\text { Overall sample } \\
(n=255)\end{array}$ \\
\hline & $\%$ \\
\hline \multicolumn{2}{|c|}{ Number of medical abortions performed within the past week } \\
\hline 0 procedures & 71.5 \\
\hline$\geq \mathrm{I}-9$ procedures per day & 15.9 \\
\hline$\geq 10$ procedures per week & 12.6 \\
\hline \multicolumn{2}{|c|}{ Number of surgical abortions performed within the past week } \\
\hline 0 procedures & 70.0 \\
\hline$\geq 1-9$ procedures per day & 20.7 \\
\hline$\geq 10$ procedures per week & 9.3 \\
\hline \multicolumn{2}{|l|}{ Home administration of misoprostol } \\
\hline Yes & 86.2 \\
\hline No & 13.8 \\
\hline \multicolumn{2}{|c|}{ Price charged for termination service (USD, mean $(95 \% \mathrm{CI})$ ) } \\
\hline Surgical abortion under 12 weeks gestation & $19.20(16.63-22.76)$ \\
\hline Medical abortion under 9 weeks gestation & $23.12(17.94-28.30)$ \\
\hline
\end{tabular}

95\% CI 17.94-28.30) and MVA (mean USD19; 95\% CI 16.63-22.76, Table 3).

When asked about preferences regarding MA versus MVA for first trimester abortion, $46.8 \%$ reported that it was the woman's choice, $45.6 \%$ preferred MA, $6.3 \%$ preferred MVA, and $1.3 \%$ did not know.

\section{Perceptions about home-based MA among providers performing both MA and MVA}

Of those who provided both MA and MVA, 55.0\% reported that women should be given the choice as to where they would like to take misoprostol, $49.3 \%$ said that women should take misoprostol at home, and $77.5 \%$ thought it was safer to take misoprostol in the health facility (Table 4).

\section{Perceptions of providers regarding attributes of MA} Advantages for women

The survey included a series of dichotomized (yes/no) unprompted questions to explore providers' perceptions regarding the advantages of MA versus MVA for women. Table 5 shows various attributes of MA cited by providers who performed MA and MVA versus those who performed MVA only. The top two advantages cited by providers in both groups were: MA is less invasive than MVA (58.6\%) and is associated with less pain (48.1\%). Less than half also 
Table 4 Providers' perceptions regarding home-based medical abortion

\begin{tabular}{lc}
\hline Perceptions & Overall sample $(\mathbf{n}=\mathbf{2 5 5})$ \\
\cline { 2 - 2 } Should women be given a choice as to whether they would like to take the \\
second treatment (misoprostol) at home or return to the health facility? \\
Home & 55.0 \\
Facility & 43.7 \\
Don't know & 1.3 \\
Based on your experience, where do you think the woman should take \\
the second treatment (misoprostol)? \\
Home \\
Facility \\
Don't know \\
Is it safer to take misoprostol at home or at health facilities? \\
At the health facility & 47.3 \\
At home & 2.5 \\
Both as safe & 5.3 \\
Don't know & 15.2 \\
\hline
\end{tabular}

mentioned that MA is associated with less pain (48.1\%), is more private/personal $(41.2 \%)$, and is more natural than MVA (40.7\%).

A significantly higher percentage of providers in the group performing both methods versus MVA only cited the following additional advantages of MA over MVA: MA can be performed at home (47.6\% versus $33.6 \% ; P=0.026)$; women can have someone with them in a private setting ( $17.7 \%$ versus $10.8 \% ; P=0.02$ ); women do not require a lot of medical supervision ( $17.4 \%$ versus $10.2 \% ; P=0.026)$; and women know what is happening having an MA (16.4\% versus $11.1 \% ; P=0.021$, Table 5).

\section{Advantages of MA for providers}

Providers were asked a series of dichotomized (yes/no) unprompted questions on the advantages of MA for providers. Subgroup analysis was conducted among providers who administered both MA and MVA (Table 6). The most common advantages cited by more than $40 \%$ of these providers were: no surgical intervention/surgical skills required (61.7\%); greater client satisfaction (61.0\%); fewer complications (46.8\%); safer than MVA (44.8\%); and shorter stay in hospital/clinic (40.3\%).

\section{Discussion}

This study is the largest survey to have been carried out among abortion providers in Vietnam (and with a high response rate), allowing our findings to be representative of public providers in this country. We found that $31.1 \%$ of providers performed both MA and MVA. Most MA providers were physicians (74.5\%), female (90.4\%), and located in urban/periurban settings $(73.3 \%)$. Our unadjusted analyses showed that female providers and providers in rural settings were less likely to provide MA than male providers and providers in urban/ periurban settings, respectively. Specialists in obstetrics and gynecology were also more likely to provide MA than providers with nursing/midwifery training. More than half of all abortion providers mentioned that the advantages of MA for women were that the procedure was less invasive than MVA and associated with less physical trauma. Among MA providers, the most frequently cited advantages of MA for providers were that no surgical skills were required $(61.7 \%)$ and client satisfaction was greater $(61.0 \%)$.

Table 5 Providers' perceptions regarding advantages of MA for women compared with surgical abortion*

\begin{tabular}{|c|c|c|c|c|}
\hline \multirow[t]{3}{*}{ Advantages for women of MA over surgical abortion } & \multirow{3}{*}{$\frac{\text { Overall }(n=905)}{\%}$} & \multicolumn{2}{|c|}{ Termination service provision } & \multirow[t]{3}{*}{$P$-value*** } \\
\hline & & $\begin{array}{l}\text { Medical and } \\
\text { surgical }(n=255)\end{array}$ & $\begin{array}{l}\text { Surgical } \\
\text { only }(n=646)\end{array}$ & \\
\hline & & $\%$ & $\%$ & \\
\hline Avoid anesthetics when choosing MA & 1.4 & 0.6 & 1.8 & 0.231 \\
\hline MA is more natural compared with surgical & 40.7 & 44.7 & 39.0 & 0.391 \\
\hline MA is associated with fewer physical traumas & 37.5 & 36.3 & 50.4 & 0.063 \\
\hline Avoid surgical intervention/equipment with MA (less invasive) & 58.6 & 66.9 & 55.1 & 0.079 \\
\hline Less pain associated with MA & 48. 1 & 40.2 & 51.5 & 0.127 \\
\hline Women know what's happening with MA & 12.7 & 16.4 & II.I & 0.021 \\
\hline MA is a more private/personal procedure & 41.2 & 49.2 & 37.8 & 0.145 \\
\hline MA is safer (associated with fewer risks) & 22.9 & 27.3 & 21.0 & 0.212 \\
\hline MA could be performed at home & 37.8 & 47.6 & 33.6 & 0.026 \\
\hline Women do not have a lot of medical supervision & 12.3 & 17.4 & 10.1 & 0.026 \\
\hline Women can have someone with them in private settings & 12.9 & 17.7 & 10.8 & 0.020 \\
\hline MA is more affordable & 15.8 & 22.2 & 13.0 & 0.140 \\
\hline
\end{tabular}

Notes: *Percentages in the table represent respondents who mentioned advantages; $* * P$-values for differences between the two groups.

Abbreviation: MA, medical abortion. 
Table 6 Providers' perceptions of advantages of medical abortion for providers among those who administer medical and surgical abortions*

\begin{tabular}{ll}
\hline $\begin{array}{l}\text { Advantages for providers of medical } \\
\text { abortion over surgical abortion }\end{array}$ & $\begin{array}{l}\text { Overall sample } \\
(\mathbf{n = 2 5 5 )}\end{array}$ \\
\cline { 2 - 2 }$\%$ \\
\hline Less medical supervision & 13.0 \\
Less medically qualified staff required & 18.8 \\
Lower risk procedure (safer) & 44.8 \\
More effective/higher success rate & 28.6 \\
More profitable & 26.6 \\
Greater client satisfaction & 61.0 \\
Fewer side effects & 26.6 \\
Fewer complications & 46.8 \\
Quicker procedure/less time managing the procedure & 32.5 \\
Shorter stay in the hospital/clinic & 40.3 \\
No surgical intervention/surgical skills required & 61.7 \\
\hline
\end{tabular}

Note: *Percentages in the table represent respondents who mentioned advantages.

The finding that more doctors administered MA than midlevel providers is expected, given that the abortion guidelines in Vietnam restrict MA provision to physicians. However, a systematic review showed no statistically significant differences in the effectiveness and safety of first trimester MA performed by mid-level providers versus physicians. ${ }^{22}$ The finding in our study that male abortion providers were more likely to perform both MA and MVA than MVA only is probably because the majority of those providing MVA in Vietnam are midwives, who are usually female. The finding that MA provision was concentrated in urban/periurban settings is consistent with findings of a 2007 assessment in Vietnam. ${ }^{23}$ Our finding that MA providers spent more time working in private health facilities than those who performed MVA only is also similar to findings of a study in India. ${ }^{13}$

The most frequently cited advantages of MA for providers in our study are in keeping with findings from previous studies. ${ }^{15,24-26}$ The fact that the majority of MA providers cited the advantage for providers being that MA results in higher client satisfaction indicates that provider perceptions of client acceptability may affect the choice of method, as previously suggested. ${ }^{14}$ The perceived efficacy and safety of MA was not associated with provision of MA in our study.

Studies have shown that cost of the abortion service, drugs, and type of provider might affect the choice of method. ${ }^{14-27}$ In 2006, a study showed that the cost of MA for women was higher than for curettage or MVA at all levels of the health care system, mainly due to drug costs in Vietnam. ${ }^{28}$ The average cost for MA was $\$ 8.80$, whereas the cost was $\$ 5.03$ for MVA, and \$5.04 for curettage. In our study, we found no statistically significant difference in the cost of MA versus MVA for first trimester abortion. However, a more accurate cost analysis (direct/indirect costs) of the two methods is needed. Almost a quarter of providers in our study currently performing MA were midwives and nurses. We were unable to assess the cost and time associated with mid-level providers versus physicians to determine accurately if service provider type has cost implications, as suggested elsewhere. ${ }^{29}$

In our survey, among those who performed MA, a large majority offered home administration of misoprostol. While home administration is not specified within the Vietnamese national abortion guidelines, this practice is consistent with recommendations of a systematic review ${ }^{30}$ and the World Health Organization guidelines. ${ }^{31}$ About half of MA providers in our study believed that women should take misoprostol at home, one of the main reasons given being the reduced time required for clinical supervision. Studies of providers regarding the option of home use of misoprostol have shown that providers believe it to be completely manageable, assuming that adequate counseling for women is available as well as provision of an on-call service. ${ }^{17-20}$ Providers in our survey also indicated that MA is a more private and confidential procedure than MVA (since it can be administered at home), and cited this as one of the main advantages for women.

Providers in our study who performed MA and MVA cited several of the MA advantages for women significantly more often than providers who performed MVA only, indicating a need for improved training and communication for all abortion providers (including mid-level providers in community health stations) regarding the advantages and disadvantages of MA for women. Previous studies have indicated that lack of adequate staff and knowledge about MA among providers are the main challenges to integrating MA into existing service provision. ${ }^{15,21}$ In addition, training mid-level providers in MA provision for rural settings may have the potential to expand choice and access to safe termination services for women living in Vietnam. Vietnam should therefore consider revising its guidelines to include MA provision by mid-level providers.

This study has certain limitations related to use of selfreported measures in a cross-sectional survey. While the measurements regarding the advantages of MA over MVA have been used extensively in other surveys of abortion providers, ${ }^{15,24-26}$ perspectives considered to be important might differ depending on the responsibilities of providers. Individuals in managerial/coordination roles might consider issues such as cost, human capacity, and client 
satisfaction as important advantages, while those with the main responsibility for service provision might be more concerned with the length of the procedure and its safety and effectiveness. We were not able to capture providers' positions within health facilities, although we found no variation in advantages of MA by type of provider (physicians versus midwives/nurses). The regions sampled were more established municipalities/provinces that might not be representative of rural/smaller provinces in Vietnam. The findings of this study cannot be generalized to other settings, since provision of abortion services is dependent on national policies. The strengths of the study included the multistage sampling strategy used to select the included provinces and health facilities, which ensured that the provinces/municipalities selected were representative of the geographic and cultural differences within Vietnam.

It is now more than a decade since its introduction in Vietnam, and provision of MA remains lower than MVA provision and is concentrated in urban/periurban settings. While the majority of abortion providers are females in Vietnam, provision of MA is concentrated among male physicians located in urban settings. Individuals who provide MA have found that the method yields high client satisfaction. Further studies are needed to explore factors affecting the preference for MA over MVA among providers and clients. Finally, since the majority of MA providers in our survey already offer home-based MA, policymakers should consider integrating home-based MA into Vietnam's policies and guidelines, to be consistent with World Health Organization guidelines.

\section{Acknowledgments}

The authors wish to thank the departments of health in Hanoi, Khanh Hoa, and Ho Chi Minh City for their support with this study, which was funded by Marie Stopes International.

\section{Disclosure}

The authors declare that they have no conflicts of interest in this work.

\section{References}

1. Forna F, Gulmezoglu AM. Surgical procedures to evacuate incomplete abortion. Cochrane Database Syst Rev. 2001;1:CD001993.

2. Berer M. Medical abortion: a fact sheet. Reprod Health Matters. 2005; 13(26):20-24.

3. Urquhart DR, Templeton AA, Shinewi F, Chapman M, Hawkins K, McGarry J. The efficacy and tolerance of mifepristone and prostaglandin in termination of pregnancy of less than 63 days gestation: UK Multicentre Study - final results. Contraception. 1997;55(1):1-5.

4. World Health Organization. Frequently asked clinical questions about medical abortion. Available from: http://www.who.int/reproductivehealth/publications/medical_abortion/faq.pdf. Accessed May 19, 2014.
5. Grossman D. Medical methods for first trimester abortion: RHL. The World Health Organization Reproductive Health Library, 2004. Available from: http://apps.who.int/rhl/fertility/abortion/dgcom/en/. Accessed May 19, 2014.

6. Ganatra B, Bygdeman M, Phan BT, Nguyen DV, Vu ML. From research to reality: the challenges of introducing medical abortion into service delivery in Vietnam. Reprod Health Matters. 2004;12(Suppl 24):105-113.

7. Elul B, Hajri S, Ngoc NN, et al. Can women in less-developed countries use a simplified medical abortion regimen? Lancet. 2001;357(9266):1402-1405.

8. Ngoc NT, Nhan VQ, Blum J, Mai TT, Durocher JM, Winikoff B. Is home-based administration of prostaglandin safe and feasible for medical abortion? Results from a multisite study in Vietnam. BJOG. 2004;111(8):814-819.

9. Nguyen TN, Blum J, Durocher J, Quan TT, Winikoff B. A randomized controlled study comparing 600 versus 1,200 microg oral misoprostol for medical management of incomplete abortion. Contraception. 2005; 72(6):438-442.

10. Nguyen M. Vietnam National Abortion Survey. Hanoi, Vietnam. The Committee for Population, Family and Children; 2002.

11. Committee for Population Family and Children [Vietnam] and ORC Macro. Vietnam Demographic and Health Survey 2002. Committee for Population, Family and Children and ORC Macro; 2003. Available from: http://dhsprogram.com/pubs/pdf/fr139/00frontmatter00.pdf. Accessed May 19, 2014.

12. Weisman CS, Nathanson CA, Teitelbaum MA, Chase GA, King TM. Abortion attitudes and performance among male and female obstetrician-gynecologists. Fam Plann Perspect. 1986;18(2):67-72.

13. Creanga AA, Roy P, Tsui AO. Characteristics of abortion service providers in two northern Indian states. Contraception. 2008;78(6): 500-506.

14. Berer M. Medical abortion: issues of choice and acceptability. Reprod Health Matters. 2005;13(26):25-34.

15. Joffe C. Reactions to medical abortion among providers of surgical abortion: an early snapshot. Fam Plann Perspect. 1999;31(1):35-38.

16. Okonofua F, Omo-Aghoja L, Bello Z, Osughe M, Agholor K. Selfreporting of induced abortion by women attending prenatal clinics in urban Nigeria. Int J Gynaecol Obstet. 2010;111(2):122-125.

17. Fielding SL, Edmunds E, Schaff EA. Having an abortion using mifepristone and home misoprostol: a qualitative analysis of women's experiences. Perspect Sex Reprod Health. 2002;34(1):34-40.

18. Clark WH, Gold M, Grossman D, Winikoff B. Can mifepristone medical abortion be simplified? A review of the evidence and questions for future research. Contraception. 2007;75(4):245-250.

19. Ho PC. Women's perceptions on medical abortion. Contraception. 2006;74(1):11-15.

20. Winikoff B, Ellertson C, Elul B, Sivin I. Acceptability and feasibility of early pregnancy termination by mifepristone-misoprostol. Results of a large multicenter trial in the United States. Mifepristone Clinical Trials Group. Arch Fam Med. 1998;7(4):360-366.

21. Ngo TD, Free C, Le HT, et al. Knowledge and provision practices regarding medical abortion among public providers in Hanoi, Khanh Hoa, and Ho Chi Minh City, Vietnam. Int J Gynaecol Obstet. 2014;124(3):216-221.

22. Ngo TD, Park MH, Free C. Safety and effectiveness of termination services performed by doctors versus midlevel providers: a systematic review and analysis. Int $J$ Womens Health. 2013;5:9-17.

23. Nha VQ, Le TPM, Ngo VQ, Nguyen QC. Medical abortion in Vietnam: policy and the situation of service provision in private and public health facilities in Ha Noi, Da Nang, and HCMC. Hanoi: Population Council; 2008.

24. Tamang A, Tamang J. Availability and acceptability of medical abortion in Nepal: health care providers' perspectives. Reprod Health Matters. 2005;13(26):110-119.

25. Kawonga M, Blanchard $\mathrm{K}$, Cooper $\mathrm{D}$, et al. Integrating medical abortion into safe abortion services: experience from three pilot sites in South Africa. J Fam Plann Reprod Health Care. 2008;34(3):159-164. 
26. Espinoza H, Abuabara K, Ellertson C. Physicians' knowledge and opinions about medication abortion in four Latin American and Caribbean region countries. Contraception. 2004;70(2):127-133.

27. Cullingworth L. A cost analysis of service provision of medical abortions in the public health sector at primary and secondary level, 2004. Available from: http://www.medicalabortionconsortium.org/pres/ lee\%20cullingworth.pdf. Accessed November 8, 2013.

28. Vietnam Ministry of Health and Program for Appropriate Technology in Health (PATH). Medical abortion in Vietnam: a cost study. Available from: http://www.path.org/publications/files/CP_vietnam_med_abt_ cost_study_rpt.pdf. Accessed May 19, 2014.
29. Creinin MD. Randomized comparison of efficacy, acceptability and cost of medical versus surgical abortion. Contraception. 2000;62(3): $117-124$.

30. Ngo TD, Park MH, Shakur H, Free C. Comparative effectiveness, safety and acceptability of medical abortion at home and in a clinic: a systematic review. Bull World Health Organ. 2011;89(5):360-370.

31. World Health Organization, Department of Reproductive Health and Research. Safe abortion: technical and policy guidance for health systems. 2nd ed. Available from: http://apps.who.int/iris/bitstream/ 10665/70914/1/9789241548434_eng.pdf. Accessed November 8, 2013.
International Journal of Women's Health

\section{Publish your work in this journal}

The International Journal of Women's Health is an international, peerreviewed open-access journal publishing original research, reports, editorials, reviews and commentaries on all aspects of women's healthcare including gynecology, obstetrics, and breast cancer. The manuscript management system is completely online and includes

\section{Dovepress}

a very quick and fair peer-review system, which is all easy to use. Visit http://www.dovepress.com/testimonials.php to read real quotes from published authors.

\footnotetext{
Submit your manuscript here: http://www.dovepress.com/international-journal-of-womens-health-journal
} 